\title{
Completing the Dissection in Melanoma: Increasing Decision Precision
}

\author{
Mark B. Faries, MD \\ The Angeles Clinic and Research Institute, Cedars Sinai Medical Center, Los Angeles, CA
}

The fact is that those who are enslaved to their sects are not merely devoid of all sound knowledge, but they will not even stop to learn!. - Galen, On the Natural Faculties, Bk. 1, Sect. 13.

For surgeons caring for patients with melanoma, treatment of regional lymph nodes has been controversial for well over a century. Over that time, two groups Galen might recognize as 'sects' developed. One group, proponents of the 'incubator' hypothesis, felt metastasis progresses sequentially, first to regional nodes and then on to distant sites. For them, early nodal surgery saves lives. The opposing 'marker' hypothesis saw lymph nodes merely as indicators of a metastatic phenotype, with surgical intervention unable to alter outcomes. As data became available to test these rival proposals, it is interesting to note how often the same information has been used to support contradictory conclusions. As the weight of available evidence has grown, controversies have diminished, and we may now be at a point where we can offer sound, rational advice to our patients as they weigh their options.

Credit for starting this controversy is generally given to Herbert Snow, who proposed 'anticipatory gland excision' in The Lancet in $1892 .{ }^{1}$ During the 20th century, his proposal was tested in a series of randomized clinical trials evaluating elective lymph node dissection. ${ }^{2-5}$ No individual trial showed a statistically significant survival benefit, but several demonstrated benefits for sizeable subgroups. This left room within the available data for varied

\footnotetext{
(C) Society of Surgical Oncology 2018
}

First Received: 27 November 2017; Published Online: 4 January 2018

M. B. Faries, MD

e-mail: mfaries@theangelesclinic.org interpretation and ongoing convictions on both sides. The development of sentinel lymph node biopsy by Morton et al. disrupted this debate by enabling lymphatic staging to be completed by a low-morbidity procedure and avoiding complete dissection for the vast majority of patients. ${ }^{6,7}$ Unequivocal clinical data, including multiple prospective multicenter trials, have confirmed the sentinel node's central role in the staging and treatment of intermediate and thick melanomas. The first Multicenter Selective Lymphadenectomy Trial (MSLT-I) also showed that, for those patients with intermediate-thickness melanomas, early removal of nodal metastases appears to improve survival. In contrast, patients with thick primary melanomas derive staging information, but survive just as well (or poorly) with delayed surgery.

Sentinel node biopsy effectively ended the debate about whether nodal staging was indicated for melanomas $>1 \mathrm{~mm}$ in thickness, but left the question of completion lymph node dissection among those with sentinel node metastases unanswered. Relatively recently, two prospective multicenter trials on that issue have been presented. MSLT-II and the DeCOG-SLT trials randomized 1939 and 483 patients, respectively, to either immediate completion dissection or observation after removal of sentinel lymph node metastases. They found no difference in melanoma-specific survival or distant metastasis-free survival based on early completion dissection. ${ }^{8,9}$ So should that be the end of completion lymph node dissection? No, but it updates our risk-benefit calculation, allowing better assessment of both sides of the equation.

On the benefits side are staging and regional disease control. The status of non-sentinel nodes is a significant, independent prognostic factor (MSLT-II hazard ratio 1.78, $p=0.005$ ). To date, no combination of other variables has been able to replace that piece of information, and, in an era of increasing adjuvant therapy choices, this information may be crucial for some patients deciding whether to pursue additional medical treatment. ${ }^{10,11}$ Immediate 
surgery also substantially decreases the risk of nodal recurrence and, by doing so, the risk of recurrence overall. Although prevention of such nodal recurrences does not appear to alter long-term survival, some patients will place a high value on avoiding any return of their disease. Early nodal recurrences in observed patients may also complicate the design of adjuvant therapy clinical trials, given the recent popularity of relapse-free survival as a primary endpoint.

In this issue of the Annals of Surgical Oncology, Postlewait et al. provide data on the cost side of the equation. They examined 239 patients who underwent axillary dissection for melanoma and demonstrated a very acceptable level of morbidity in terms of wound infection (16.9\%), seroma $(15 \%)$, frozen shoulder $(11 \%)$, and wound dehiscence $(1.2 \%)$. The study is limited by its retrospective nature, which could lead to overreporting of some morbidities (e.g. infection and frozen shoulder) and underreporting of others (e.g. lymphedema). Lymphedema rates in the current study (5.1\%) were comparable with those seen in prospective assessments such as MSLT-I (7.2\%) and the Sunbelt Trial $(4.6 \%) .{ }^{12,13}$ The edema risk with surgery appears acceptably moderate, although MSLT-II makes it clear that the risk is higher with surgery than with observation.

Edema may also be more frequent for those undergoing delayed, therapeutic dissection, as was the case for that group in the MSLT-I trial, with a rate of $12.5 \% .^{12}$ It is interesting to note that lymphedema in melanoma may be less frequent than in breast cancer, where rates are 12-20\%. ${ }^{14,15}$ The current report only examines the axilla. Morbidity of dissection varies across nodal basins, with the lowest morbidity 'cost' for neck dissections and the highest in the inguinal basin. ${ }^{12}$ Use of a minimally invasive approach to inguinal dissection appears to reduce the risk of short-term morbidity, but it is not clear whether the long-term risk of edema will be altered. ${ }^{16} \mathrm{~A}$ final aspect of this calculation is financial, including direct treatment expenses as well as indirect costs due to patients' time away from work. The current report does not shed light on this and additional analyses would be desirable.

Although our decisions are now much more evidencebased, they would be even simpler if we were able to predict with precision which patients definitely had, or did not have, non-sentinel node metastases. Various schemes have been proposed for this and generally include the extent of disease at the primary site and within the sentinel node. However, there has been limited agreement across studies for predictive factors and we have yet to develop a highly reliable algorithm. ${ }^{17-19}$

It is too soon to know how advances in adjuvant systemic therapy will alter consideration of completion dissection. All of the data we have on those therapies were derived from patients who had undergone dissection. It is possible that more effective adjuvant therapy will reduce regional recurrence in those electing observation, as appears to be the case for patients with breast cancer. However, the very availability of these therapies may increase the value of complete surgical staging in determining who is an optimal candidate.

Hopefully the wealth of data now available on the pros and cons of nodal surgery in melanoma have reduced the number of surgeons who are 'true believers'. Completion lymph node dissection remains an option for patients with sentinel node metastases in melanoma. ${ }^{20}$ The absence of a survival benefit for the procedure should significantly reduce the proportion of patients who elect to have the additional surgery, but a reasonable patient may weigh the benefits of the procedure in staging and regional disease control relative to the risks and choose to go ahead. We must all 'stop to learn' so that every individual patient can find the option that is right for them.

\section{REFERENCES}

1. Snow HM. Melanotic cancerous disease. Lancet. 1892;140: 869-922.

2. Balch C, Soong S, Ross M, et al. Long-term results of a multiinstitutional randomized trial comparing prognostic factors and surgical results for intermediate thickness melanomas (1.0-4.0 mm). Ann Surg Oncol. 2000;7:87-97.

3. Cascinelli N, Morabito A, Santinami M, MacKie RM, Belli F. Immediate or delayed dissection of regional nodes in patients with melanoma of the trunk: a randomised trial. WHO Melanoma Programme. Lancet. 1998;351:793-6.

4. Veronesi U, Adamus J, Bandiera DC, et al. Delayed regional lymph node dissection in stage I melanoma of the skin of the lower extremities. Cancer. 1982;49:2420-30.

5. Sim FH, Taylor WF, Pritchard DJ, Soule EH. Lymphadenectomy in the management of stage I malignant melanoma: a prospective randomized study. Mayo Clin Proc. 1986;61:697-705.

6. Morton D, Wen D, Wong J, et al. Technical details of intraoperative lymphatic mapping for early stage melanoma. Arch Surg. 1992;127:392-9.

7. Morton DL, Thompson JF, Cochran AJ, et al. Final trial report of sentinel-node biopsy versus nodal observation in melanoma. $N$ Engl J Med. 2014;370:599-609.

8. Faries MB, Thompson JF, Cochran AJ, et al. Completion dissection or observation for sentinel-node metastasis in melanoma. N Engl J Med. 2017;376:2211-22.

9. Leiter U, Stadler R, Mauch C, et al. Complete lymph node dissection versus no dissection in patients with sentinel lymph node biopsy positive melanoma (DeCOG-SLT): a multicentre, randomised, phase 3 trial. Lancet Oncol. 2016;17:757-67.

10. Leung AM, Morton DL, Ozao-Choy J, et al. Staging of regional lymph nodes in melanoma: a case for including nonsentinel lymph node positivity in the American Joint Committee on Cancer staging system. JAMA Surg. 2013;148:879-84.

11. Reintgen M, Murray L, Akman K, et al. Evidence for a better nodal staging system for melanoma: the clinical relevance of metastatic disease confined to the sentinel lymph nodes. Ann Surg Oncol. 2013;20:668-74.

12. Faries MB, Thompson JF, Cochran A, et al. The impact on morbidity and length of stay of early versus delayed complete 
lymphadenectomy in melanoma: results of the multicenter selective lymphadenectomy trial (I). Ann Surg Oncol. 2010;17:3324-9.

13. Wrightson WR, Wong SL, Edwards MJ, et al. Complications associated with sentinel lymph node biopsy for melanoma. Ann Surg Oncol. 2003;10:676-80.

14. Olson JA Jr, McCall LM, Beitsch P, et al. Impact of immediate versus delayed axillary node dissection on surgical outcomes in breast cancer patients with positive sentinel nodes: results from American College of Surgeons Oncology Group Trials Z0010 and Z0011. J Clin Oncol. 2008;26:3530-5.

15. DiSipio T, Rye $S$, Newman B, Hayes S. Incidence of unilateral arm lymphoedema after breast cancer: a systematic review and meta-analysis. Lancet Oncol. 2013;14:500-15.

16. Jakub JW, Terando AM, Sarnaik A, et al. Safety and feasibility of minimally invasive inguinal lymph node dissection in patients with melanoma (SAFE-MILND): report of a prospective multiinstitutional trial. Ann Surg. 2017;265:192-6.
17. Murali R, Desilva C, Thompson JF, Scolyer RA. Non-sentinel node risk score (N-SNORE): a scoring system for accurately stratifying risk of non-sentinel node positivity in patients with cutaneous melanoma with positive sentinel lymph nodes. $J$ Clin Oncol. 2010;28:4441-9.

18. Wevers KP, Murali R, Bastiaannet E, et al. Assessment of a new scoring system for predicting non-sentinel node positivity in sentinel node-positive melanoma patients. Eur J Surg Oncol. 2013;39:179-84.

19. Sabel MS, Griffith K, Sondak VK, et al. Predictors of nonsentinel lymph node positivity in patients with a positive sentinel node for melanoma. J Am Coll Surg 2005;201:37-47.

20. Wong SL, Faries MB, Kennedy EB, et al. Sentinel lymph node biopsy and management of regional lymph nodes in melanoma: American Society of Clinical Oncology and Society of Surgical Oncology clinical practice guideline update. Ann Surg Oncol. 2017 https://doi.org/10.1245/s10434-017-6267-7. 